\title{
A função de diretor de escola pública no estado do acre e sua política de formação e remuneração
}

\author{
The role of the head teacher in public schools in the state of acre and his/her \\ training and remuneration policy \\ Función del director de escuela pública em el estado de acre y sus políticas de \\ formación y remuneración

\section{LÚCIA DE FÁTIMA MELO \\ MÁRIO ROBERTO MACHADO TORRES}

Resumo: $\mathrm{O}$ trabalho analisa a função de diretor de escola pública no Estado do Acre e sua política de formação e remuneração, no período de 1996 a 2016. A análise se fundamenta em pesquisa bibliográfica, documental e empírica, contando com o aporte teórico dos estudos de Paro (2000, 2003, 2015); Souza (2006; 2010a; 2010b); Oliveira (2004, 2005, 2010 e 2015); Ball (1998); Cruz (2015); Melo (2010) dentre outros. Os aspectos conclusivos da pesquisa indicam que a função não atende aos anseios dos diretores. A formação é considerada insuficiente e a remuneração baixa, diante das responsabilidades que os diretores passaram a ter no conjunto das reformas educacionais ensejadas por uma nova gestão pública.

Palavras-chave: Diretor de escola; política de formação; política de remuneração.

Abstract: The paper analyzes the role of the head teacher in public schools in the State of Acre and his/her training and remuneration policy from 1996 to 2016. The analysis is based on bibliographical research, documentary and empirical research, counting on the theoretical contribution of the Paro studies (2000, 2003, 2015); Souza (2006; 2010a; 2010b); Oliveira (2004, 2005, 2010 e 2015); Ball (1998); Cross (2015); Melo (2010) among others. The conclusive aspects of the research show that the role of the head teacher does not meet his/her desires. The training is considered insufficient and the paid is low ahead of the responsibilities the head teachers have achieved in the package of educational reforms occasioned by a new public management.

Keywords: Head teacher; training policy; remuneration policy.

Resumen: El trabajo analisa la función del directores de escuela pública en el Estado de Acre y sus políticas de formación y remuneración, en el período correspondente a 1996 y 2016. El análisis se fundamenta en una pesquisa bibliográfica, documental y empírica, con el aporte teórico de los estudios de Paro (2000, 2003, 2015); Souza (2006; 2010a; 2010b); Oliveira (2004, 2005, 
2010 e 2015); Ball (1998); Cruz (2015); Melo (2010) entre otros. Los aspectos conclusivos de la pesquisa indican que la funçión no atiende al anhelo de los directores. La formación es considera insuficiente y la remuneración baja frente a las responsabilidades que los directores pasaram a tener en el conjunto de las reformas educacionales motivadas por una nueva gestión pública.

Palabras clave: Director de escuela; política de formación; política de remuneración.

\section{INTRODUÇÃO}

A pesquisa analisa a função de diretor de escola pública no Estado do Acre e sua política de formação e remuneração. A gestão da escola pública no Estado do Acre encontra-se marcada por uma reforma educacional cujo marco inaugural se dá com a ascensão ao poder de uma Frente de Partidos denominada Popular, capitaneada pelo Partido dos Trabalhadores no ano de $1999^{1}$. Tal reforma foi responsável por mudanças substanciais no sistema educacional acriano, com repercussões na escola e no trabalho do diretor. A análise coloca em relevo o contexto em que a reforma foi concebida, as mudanças que ensejou na gestão escolar e as repercussões na função de diretor, notadamente nos aspectos da política de formação e remuneração.

O entendimento, neste trabalho, é o de que as políticas educacionais, dentre elas as políticas de gestão, não são neutras, elas se realizam em um contexto histórico contraditório, em que classes e grupos se confrontam em defesa de seus interesses. Resumidamente, é possível afirmar que, em âmbito geral, o contexto contemporâneo é marcado por transformações oriundas das mudanças nas relações sociais de produção, no processo de reestruturação produtiva e na chamada reforma do Estado, tendo como um dos seus eixos, no campo das políticas educativas, o surgimento de uma nova regulação².

Tal regulação emergiu em consequência do ciclo de reformas que muitos países conheceram nos seus sistemas educacionais, a partir dos anos de 1990, com o Estado assumindo uma nova função redimensionada pelas políticas neoliberais, pelas quais, aos poucos, se exime de ser executor de ações para controlar e avaliar as políticas públicas. Essa nova função, assumida pelo Estado, tem exigido mudanças no seu aparelho administrativo, o modelo de gestão burocrática, até então predominante, vem sendo substituído por um modelo de gestão gerencial. Esse processo de reforma, que tem repercussões na gestão escolar, é impulsionado,

\footnotetext{
1 Uma visão mais detalhada sobre a Reforma do Sistema Educacional acriano pode ser visto em Melo (2010) e Damasceno (2010).

2 Para melhor compreensão do conceito de Regulação e suas implicações na esfera da educação, recomendam-se trabalhos de Barroso (2005) e Oliveira (2005).
}

812 - RBPAE - v. 33, n. 3, p. 811 - 833, set./dez. 2017 
em última instância, pela chamada Nova Gestão Pública (NGP) ou administração pública gerencial, que surgiu na década de 1980 e, no Brasil, passou a ser implantada a partir de 1995, com a reforma do Estado brasileiro. A proposta da NGP é combater os vícios oriundos do patrimonialismo e da burocracia, aliada aos princípios de eficiência e eficácia, entre outros. "O Estado gerencial combate o Estado de bem-estar social e cria as bases para políticas públicas que redesenham a relação entre sociedade civil e Estado” (LIMA e GANDIN, 2012, p.69).

A lógica gerencialista não se aplica automaticamente a todas as ações do Estado sem que exista um processo de mediação. Essa lógica é alicerçada em teorias e técnicas de gerência empresarial, do "culto da excelência" (BALL, 1998) e da lógica do mercado, o que acarreta profundas modificações no Estado. A Nova Gestão Pública caracteriza-se por uma racionalidade em que princípios como a autonomia escolar, a prestação de contas, a gestão baseada em resultados, fronteiras tênues entre o público e o privado, têm interferido profundamente na regulação dos sistemas educativos, atingindo as escolas e sua gestão.

Isso pelo fato de tal racionalidade vir acompanhada de maior descentralização administrativa e financeira, atribuindo às escolas maior autonomia institucional e responsabilidades pelos seus processos. A ênfase nas avaliações dos resultados acadêmicos tem dirigido cada vez mais a gestão escolar, pois elas passam a funcionar como um importante mecanismo de regulação do sistema. Vivemos um momento da existência de ambientes competitivos dentro das instituições públicas, com objetivos claros de produtividade.

Discutir o trabalho do diretor, em face dessa nova realidade, passa por abordar questões afetas à política educacional em curso e aos desdobramentos gerados ao processo de construção de uma escola mais democrática. Grande parte da literatura direcionada à gestão escolar, na atualidade (OLIVEIRA, 2004; SHIROMA, 2004; CASTRO, 2007), enfatiza que as modificações empreendidas nas últimas décadas na gestão e na organização da escola têm resultado numa reestruturação do trabalho docente.

Concordam que, ao mesmo tempo em que os novos modelos de gestão defendidos pelas reformas educacionais preconizam uma gestão escolar mais descentralizada, com certo nível de autonomia dos profissionais que ali atuam, advogando pela ampliação da participação da comunidade escolar nas suas decisões - o que em tese são elementos que caracterizam uma gestão democrática -, vem ocorrendo uma sobrecarga de trabalho para as unidades escolares e para aqueles que delas fazem parte. Tem sido consenso que o excesso de atividades tem atingido, particularmente, aqueles que exercem funções tanto na gestão da sala de aula, como na gestão da escola, a exemplo dos diretores escolares. 
Tratar das discussões relativas à gestão da escola e da necessidade de construção de relações mais democráticas no seu interior, em um contexto no qual impera a lógica empresarial, dentro dos preceitos da Nova Administração Pública, não tem sido nada fácil. Principalmente, quando governos alinhados às forças mais progressistas, a exemplo de Luis Inácio Lula da Silva (20032010) e Dilma Rousseff (2011-2016), assumiram uma determinada agenda sem conseguir romper com essa lógica. Oliveira (215) ressalta que, apesar dos avanços conquistados na ampliação de direitos, diminuição da pobreza e maior inserção social, as mudanças promovidas pelos "governos democrático-populares" não romperam a racionalidade anterior, o que instaura contradição fundamental no setor educacional.

Essa situação se repete no Estado do Acre com a implementação de políticas de gestão cujas dimensões encontram relação com a chamada Reforma do Estado Brasileiro e a defesa de uma Nova Gestão Pública (NGP). Esse processo foi iniciado pelo então governador Jorge Viana (1999-2006), que propôs uma nova governança para a administração pública, bem como uma nova governança para as escolas estaduais ${ }^{3}$. Tal processo teve continuidade com seu sucessor, Arnóbio Marques Júnior (2007-2010) e, atualmente, seu irmão Sebastião Viana (2011-2018) dá continuidade a essas políticas, agora de uma forma muito mais alinhada aos princípios gerenciais do que fizeram seus antecessores.

Hoje, é possível afirmar que aquela concepção de gestão, fruto das lutas em prol da democratização do Brasil que, no Acre, eram bastante alargadas no final da década de 1980 e inicio da década de 1990, principalmente, a partir do governo Sebastião Viana ${ }^{4}$, vem sendo esmaecida, passando a não contemplar a perspectiva de gestão democrática e, sim, alguns postulados de gestão compartilhada, sustentada pela hierarquização, pela participação tutelada e pelo controle verticalizado das decisões na estrutura escolar. Essa nova gestão escolar, inspirada nos princípios da Nova Administração Pública, advoga uma lógica

3 A proposta de uma nova governança para as escolas estaduais foi apresentada por intermédio da Lei 1.513/2013, que extinguiu a figura do Vice-Diretor de Escola e criou um Núcleo de Gestão representado pelo Diretor, Coordenador de Ensino e Coordenador Administrativo. Nessa nova estrutura, o Conselho Escolar passou a ocupar papel central na hierarquia de poder com a organização pedagógico-administrativa das unidades de ensino, composta pela seguinte estrutura: I -Conselho Escolar; e II - Diretor. (Cf. Art. $3^{\circ}$ da referida lei).

4 Essa situação pode ser ilustrada com a promulgação, em seu governo, da Nova Lei de Gestão Democrática das Escolas Estaduais - Lei 3.141/2016. Um dos pontos mais polêmicos dessa Lei é que agora não precisa ser professor para ser diretor. Os servidores não docentes, com formação em nível superior na área de administração pública, administração escolar ou processos escolares, também podem participar das etapas para o provimento da função $\left(\S 1^{\circ}\right.$ do Art. 11). A lei muda, também, a hierarquia de poder até então existente nas escolas e cria uma outra instância deliberativa, com a organização pedagógico-administrativa das unidades escolares passando a ser composta pelas seguintes instâncias e respectivas funções: I - direção escolar que envolve: a) diretor; b) coordenador de ensino; c) coordenador administrativo; d) coordenadores pedagógicos; e e) secretário escolar. II - conselho escolar; e III - comitê executivo. (Cf. Art. $4^{\circ}$ da referida lei). 
empresarial para dentro da escola. Os princípios gerenciais supervalorizam os resultados, os índices, acoountabiliity ${ }^{5}$, a responsabilização, a competitividade, e são, em grande parte, inspirados em uma política dos Estados Unidos, conforme anuncia Freitas:

\begin{abstract}
Tem consequência quando se diz que vamos introduzir a lógica privada dentro da área educacional, porque teremos de seguir as regras do mercado, e elas são implacáveis: ou as seguimos ou vamos à falência. Para não falir, introduz-se essa lógica dentro das empresas educacionais, porque se as empresas administrarem as escolas públicas precisarão ter maior número de turmas e precarizar o professor. (...) Então, nós temos de ter cuidado com as políticas que estamos implantando por aqui. Não é porque é bom para os americanos que é bom para o Brasil. Até porque nem é tão bom assim nem para eles. (FREITAS, 2013).
\end{abstract}

Vai ser neste contexto que questões ligadas à responsabilização pelos resultados, prestação de contas, uso otimizado de recursos, gerência, eficácia, performatividade, meritocracia e privatização tornam-se cada vez mais comuns nos discursos educacionais. Por outro lado, não com a mesma intensidade, são levantados questionamentos no tocante às condições de trabalho, à formação e à remuneração docente, elementos fundamentais quando se almeja uma escola eficiente e um ensino de melhor qualidade.

Desde a década de 1990, a gestão da escola e, em especial, o trabalho do Diretor, vêm sendo objeto de debates entre diferentes setores sociais. Esses debates, embora não partilhem da mesma perspectiva teórica e política, convergem para a importância atribuída à gestão da escola como instrumento para a promoção da qualidade na educação. No centro da gestão escolar, encontra-se o diretor.

Dentro dessa perspectiva, a discussão relativa à sua formação e remuneração é importante e faz parte da pauta permanente no debate nacional em defesa do reconhecimento e da valorização dos profissionais do magistério (BASSI et al. 2012) e são aspectos fundamentais na luta pela profissionalização. Oliveira (2010) destaca que os estudos sobre a profissão docente possuem duas vertentes. A primeira, denominada pedagógica humanista, centra seu foco na formação como aspecto central da profissionalização. A segunda, identificada na perspectiva sociológica, tem a identidade profissional compreendida na relação com as atividades laborais, ou seja, nas condições de trabalho.

No Estado do Acre, esse debate foi fortalecido com a aprovação das leis 1.201/96 e 1.513/03, que normatizam a gestão democrática na rede estadual. No Acre e em sua rede Pública de Ensino não existe a carreira do Diretor de Escola

5 O termo acoountabiliity tem sido traduzido como transparência, responsabilização, rendição de contas e outros. Na falta de concordância sobre a melhor tradução, mantem-se o termo em inglês. 
(como é o caso do Estado de São Paulo), mas a função. Ser professor na rede de Ensino do Acre na vigência da lei 1.513/03 era pré-requisito para ocupar a função de diretor escolar (Art. $6^{\circ}$ da Lei 1513/03).

Esse requisito foi alterado por força da Lei 3.141 de 22 de Julho de 2016, que "dispõe sobre a gestão democrática das unidades escolares da rede pública estadual de educação básica do Acre". A lei passou a permitir que, além do professor, o servidor não-docente com formação em nível superior na área de administração pública, administração escolar ou processos escolares, possa participar das etapas para o provimento da função de diretor na rede estadual do Acre ( $\int 1^{\circ}$ do Art. 11), contrariando o Parágrafo $1^{\circ}$ do Art. 67 da LDB, que estabelece a experiência docente como pré-requisito para o exercício profissional de quaisquer outras funções de magistério, dentre as quais a direção de escola.

Neste texto, escrito a partir de pesquisa desenvolvida na rede estadual de educação do Acre, apresenta-se parte das discussões que envolvem a temática do Diretor de Escola nesse Estado, buscando responder a alguns questionamentos: Como se configura a função de diretor de escola pública no Estado do Acre e quais as políticas de formação e remuneração desenvolvidas? Estas políticas correspondem efetivamente às reais necessidades do diretor escolar?

O Artigo encontra-se organizado em torno de três eixos. O primeiro coloca em evidência a pesquisa e seu contexto, situando o Estado do Acre e sua rede de ensino. O segundo apresenta o perfil dos sujeitos que participaram da pesquisa (Diretores Escolares) e o terceiro foca as questões mais candentes relativas à função, formação e remuneração dos diretores escolares. Por fim, acrescentam-se algumas considerações finais a título de conclusão do texto.

\section{A PESQUISA E SEU CONTEXTO}

O referencial empírico para a investigação foi a rede acriana de Ensino e suas unidades educacionais situadas no perímetro urbano do município de Rio Branco, contemplando critérios de abrangência local e especificidades de desenhos de políticas educacionais que mereçam ser conhecidas. A escolha da Capital Rio Branco se deu, principalmente, em virtude da facilidade do acesso às escolas públicas e por se tratar do município acriano que possui o maior número de escolas estaduais, num total de 94 (noventa e quatro).

Como instrumento de coleta de dados, foi utilizado um questionário, com questões abertas e fechadas, previamente estabelecidas e devidamente 
testadas. Sua aplicação foi feita junto a escolas que fazem parte das regionais ${ }^{6} \mathrm{em}$ que o município de Rio Branco encontra-se dividido, tendo como respondentes os sujeitos responsáveis pela direção das unidades educacionais da rede pública do Estado do Acre.

Em virtude da necessidade de operacionalização da pesquisa, definiramse como critérios para escolha dos sujeitos: tempo de atuação no magistério, tempo de ocupação da função de diretor e formação. Ao todo, foram nove respondentes, sendo um de cada regional, considerando, ainda, como critério, o Índice de Desenvolvimento da Educação Básica - IDEB. Levou-se em consideração esse indicador para a escolha das escolas, sendo observadas as que obtiveram IDEB's maiores, menores e intermediários. Das nove escolas escolhidas, 03 (três) atendem os anos iniciais do EF, 03 (três) os anos finais do EF e 03 (três) o Ensino Médio.

A pesquisa valeu-se, também, de análise documental da Legislação Federal e Estadual que regulamenta a função de Diretor de Escola, tais como: a) Federal: CF/1988; Lei no 9394/96 (LDB); Lei n 11.738/08 (Piso Profissional); Lei nº. 8.112/90 (Regime Jurídico Único dos Servidores Civis da União, Autarquias e Fundações Públicas Federais) e b) Estadual: Constituição Estadual (ACRE, 1989); LC nº. 14/87 (PCCS) e LC nº. 67/99 (PCCR); LC nº 1.201/96 (Gestão Democrática); LC no. 1513/03 (Gestão Democrática); Instrução Normativa n. 04/2004 (Diretrizes Administrativas e Pedagógicas da SEE); Decretos n. 5.592/2010 e 3.191/2014 (regulamentam os prêmios de VDP - Prêmio Anual de Valorização e Desenvolvimento Profissional e VDG - Prêmio Anual de Valorização e Desenvolvimento Profissional da Gestão Escolar do Acre) e a atual Lei de Gestão Democrática (Lei 3.141/2016).

\section{SITUANDO O ACRE E SUA REDE DE ENSINO PÚBLICO}

O Estado do Acre é um dos mais novos Estados da Federação Brasileira. Foi elevado à categoria de Estado em 15 de Junho de 1962, por lei sancionada pelo Presidente João Goulart. É o $15^{\circ}$ em extensão territorial, com uma superfície de 164.221,36 km2, correspondendo a 4,26\% da região Norte e a 1,92\% do território nacional. Localiza-se no sudoeste da Região Norte, fazendo limites internacionais com o Peru (O) e a Bolívia (S) e por divisas estaduais com os Estados do Amazonas

\footnotetext{
6 Para Melhor realizar acompanhamento das escolas, a equipe da Gestão da Secretaria de Educação do Estado do Acre, em 2015, dividiu o perímetro urbano da capital em 9 (nove) Regionais (antes eram 7), sendo que cada uma tem um coordenador pra a interlocução entre a Escola e o órgão central. São elas: Regional do Centro (que engloba 10 escolas); Regional do Universitário (10 escolas); Regional da Baixada I (10 escolas); Regional da Baixada (10 escolas); Regional do São Francisco (9 escolas); Regional do Tancredo Neves (9 escolas); Regional do Bosque (8 escolas), Regional do Belo jardim (10 escolas); Regional do Quinze (10 escolas).
} 
(N) e Rondônia (L). Possui 22 municípios, sendo os mais populosos: Rio Branco, Cruzeiro do Sul, Sena Madureira, Tarauacá e Feijó (ACRE, 2013).

De acordo com o censo (IBGE 2010/), o Acre possui uma população de 733.559 habitantes, dos quais 532.279 (72,56\%) residem na zona urbana e 201.280 $(27,44 \%)$ residem na zona rural do Estado. Quase a metade dessa população vive na capital Rio Branco, totalizando 336.038 habitantes. A quase totalidade vive na cidade, perfazendo um total de $308.545(91,82 \%)$ e $27.493(8,17 \%)$ na zona rural de Rio Branco (ACRE, 2013). A estimativa do Censo Demográfico do IBGE (2010) é de que o Acre possui em 2016, 816.687 habitantes.

Os principais indicadores sociais do Estado apresentam os seguintes números: taxa de analfabetismo de 13,8\% e Índice de Desenvolvimento Humano (IDH) de 0,719 (IBGE, 2014); Índice de Desenvolvimento Humano-Educação (IDH-E) de 0,559 (IBGE, 2010). Tais indicadores levam em consideração a situação educacional da população adulta e a população em idade escolar (crianças e jovens), a alfabetização e o índice de frequência à escola. O número da matrícula inicial em 2015, de acordo com o Censo Escolar foi de 272.943 alunos, sendo o maior número no Ensino Fundamental, com 162.822 estudantes, 14.935 docentes e 1.649 estabelecimentos de ensino.

Em relação ao Índice da Educação Básica - IDEB, a rede estadual de ensino apresenta os resultados constantes na tabela abaixo:

\section{Tabela 1 - Índice Desenvolvimento da Educação Básica (IDEB) da Rede Pública do Acre-2015}

\begin{tabular}{|c|c|c|c|}
\hline & $\begin{array}{c}\text { Anos Iniciais }\left(1^{\circ} \text { ao } 5^{\circ}\right. \\
\text { ano) }\end{array}$ & $\begin{array}{c}\text { Anos Finais }\left(6^{\circ} \text { ao } 9^{\circ}\right. \\
\text { ano) }\end{array}$ & Ensino Médio \\
\hline IDEB alcançado & 5,5 & 4,4 & 3,5 \\
\hline $\begin{array}{c}\text { Meta projetada pelo } \\
\text { MEC }\end{array}$ & 4,7 & 4,7 & 3,9 \\
\hline
\end{tabular}

Fonte: MEC/INEP- adaptada da SEE.

A Rede acriana de ensino, conforme demonstra a tabela acima, superou a meta para os anos iniciais do EF, porém ficou abaixo das metas estabelecidas pelo MEC, tanto para os anos finais do EF, como para o Ensino Médio. O Ensino Médio vem se tornando um dos grandes desafios do ensino público acriano nesse aspecto, uma vez que, tanto na versão 2013, quanto na de 2015, sequer a meta do MEC foi alcançada. 


\section{O PERFIL DOS DIRETORES PARTICIPANTES DA PESQUISA}

Nas escolas pesquisadas, em relação ao gênero, observa-se que a maioria dos diretores é do sexo feminino (55,5\%) e 45,5\% do sexo masculino. Quando se amplia o universo para todo o Estado, essa diferença permanece em favor das mulheres. $\mathrm{Na}$ rede estadual, temos $64,6 \%$ de mulheres exercendo a função de diretora e $35,4 \%$ de homens. Esses resultados se alinham ao perfil do diretor escolar do Brasil de acordo com Souza (2006), que aponta a forte marca do gênero no quadro geral no Brasil, e que segundo esse autor é o seguinte: 78,2\% das direções escolares ocupadas por mulheres e $21,8 \%$ por homens. Comparando todas as regiões brasileiras, Norte e Nordeste apresentam o maior número de homens na direção, chegando a quase $33 \%$ no Norte. Pesquisas ${ }^{7}$ sobre gênero na profissão docente têm apontado para a feminilização da profissão nas escolas brasileiras, segundo Cruz (2015). São 72,8\% professoras contra 22,8\% de professores, segundo Souza (2006). Percebe-se uma simetria no perfil dos diretores e professores no aspecto Gênero nas escolas brasileiras.

\section{Gráfico 1 - Comparação Diretores por Sexo entre o Acre e o Brasil}

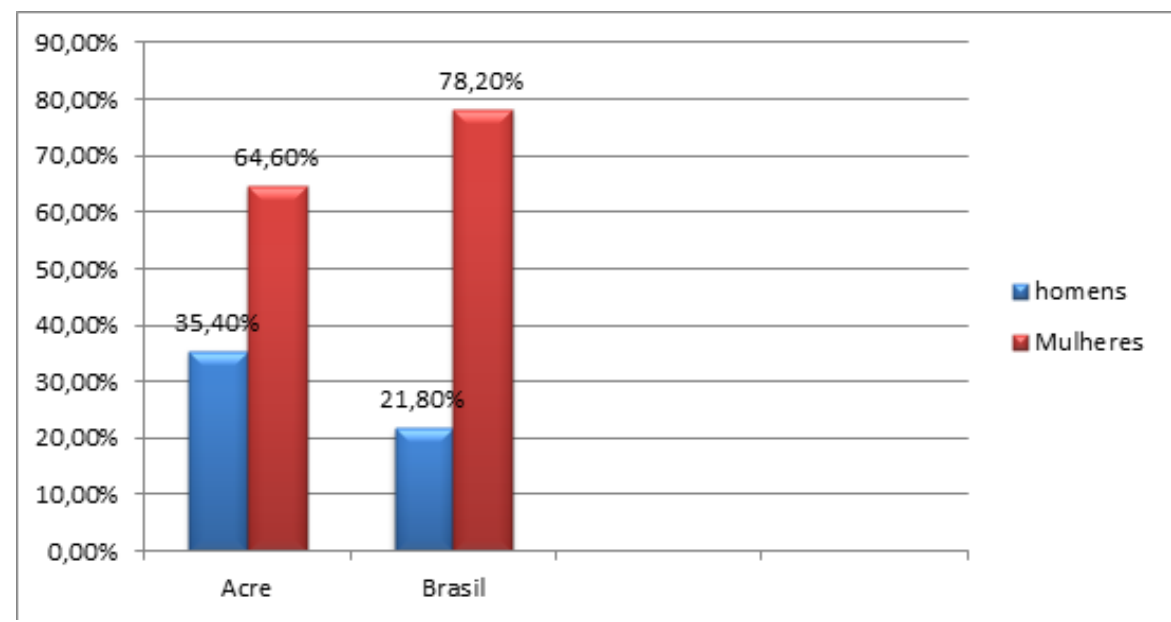

Fonte: SEE/2016 e Souza (2006) - elaborado pelos autores

\footnotetext{
7 Ver: O Perfil dos professores brasileiros: o que fazem, o que pensa, o que almejam. UNESCO
} 2004 (CRUZ, 2015). 
Cabe destacar os casos dos municípios acrianos de Feijó (7 escolas), Epitaciolândia (4 escolas), Jordão (2 escolas) e Marechal Thaumaturgo (1 escola), nos quais as funções de diretores escolares da rede estadual de ensino são todas ocupadas por mulheres.

Em relação à idade, a grande maioria dos diretores que participaram da pesquisa encontra-se na faixa etária de 43 a 52 anos $(74,4 \%)$, enquanto outra parte (25,6\%) situa-se entre 53 a 63 anos. Como todos possuem mais de 20 anos de magistério na docência da Rede Pública do Acre, é possível afirmar que iniciaram suas carreiras ainda jovens, aproximadamente na faixa etária dos 20 anos de idade e que são profissionais experientes. Segundo Souza (2006), inicia-se a carreira em média até os 25 anos de idade. Descontando oito anos de mandato na direção de escola (equivalente a dois mandatos), temos profissionais com mais de 12 anos na docência.

A experiência desses profissionais na função de direção de escola varia de quatro a doze anos. Seis desses professores estão atuando na função de diretor entre quatro a oito anos, dois estão no primeiro mandato e apenas um tem experiência de doze anos na direção, ou seja, três mandatos, embora não consecutivos.

Sobre o tempo que estão atuando no exercício da função de diretor, sete diretores $(77,78)$ exercem entre quatro e oito anos, portanto, estão no segundo mandato naquela escola, enquanto dois $(22,22 \%)$ estão com menos de quatro anos, ou seja, no primeiro mandato. Em relação ao estado civil, cinco $(55,56 \%)$ diretores são casados, dois $(22,22 \%)$ divorciados e dois $(22,22 \%)$ solteiros e têm em média cerca de dois filhos.

Quanto ao vínculo de trabalho com o Estado, para quase todos (89\%) se deu por meio de concurso público e os outros $11 \%$ foram contratados antes da $\mathrm{CF} / 88$, não se submetendo, portanto, ao concurso. O mesmo percentual de $89 \%$ é aplicado aos professores detentores de apenas um vínculo empregatício com o Governo do Estado e, desses, 25\% possui outro contrato na rede municipal de Rio Branco.

\section{A FUNÇÃO}

A forma de provimento à função de diretor de escola pública no Acre se dá com a combinação de duas modalidades: seleção e eleição (esquema misto). A primeira fase é realizada por meio de curso de formação com exame de 
certificação ${ }^{8}$. Os aprovados nesta fase participam da segunda etapa, que consiste na escolha pelo voto direto da comunidade escolar.

Cruz (2015), ao analisar o esquema misto como provimento à função de diretor, conclui que "tende a satisfazer os partidários do concurso público e da eleição, uma vez que além de avaliar a competência técnica do candidato, também possibilita a aferição da liderança do futuro diretor com a participação da comunidade escolar" (CRUZ, 2015, p. 74). Nessa forma de escolha, portanto, são valorizadas tanto a capacidade técnica como a liderança do diretor. Assim, o Sistema de Ensino Estadual do Acre, ao definir essa modalidade como forma de escolha do dirigente escolar, busca profissional com este perfil: um diretor com conhecimentos técnicos na área de administração e educação, bem como um líder que faça a mediação entre as políticas e os fins educacionais na escola, contando com a legitimidade conferida pela comunidade escolar.

É uma modalidade que vem crescendo no cenário nacional. Segundo Cruz (2015), é utilizada em 22\% das escolas de Ensino Fundamental no Brasil, com destaque para o Distrito Federal (68\%) e nos estados do Acre (63,9\%) e Minas Gerais (39\%). Essa modalidade de escolha de diretor é considerada por Libâneo (2001) como a melhor forma de provimento à função, cujo processo deve conter: 1) prova escrita; 2) avaliação da formação profissional e competência técnica; 3) eleições, da quais a comunidade escolar deve participar.

Quanto aos níveis de satisfação com a função, a maioria dos diretores pesquisados $(55,5 \%)$ está satisfeita com a função, apesar de considerá-la mal organizada e pouco atraente para bons profissionais $(66,66 \%)$ e destaca como aspectos positivos da função: a participação dos pais na comunidade escolar; os resultados alcançados com seu trabalho; a formação como critério para ser diretor (curso de certificação); o princípio da gestão democrática; aprendizagem e os desafios enfrentados no cotidiano. Já os aspectos negativos são detalhados nas seguintes categorias: má remuneração; desvalorização profissional; falta de apoio da SEE; falta das condições necessárias para a realização do trabalho; aumento de trabalho, de responsabilidade e de cobrança e busca pela bonificação, sem se interessar de fato pela prática educativa e pelo exercício da gestão democrática.

Sobre a natureza do trabalho do diretor escolar, o aspecto administrativo foi apontado pela maioria $(44,44 \%)$ como sendo o principal aspecto a lhe consumir no exercício da função, provavelmente por ser nesse aspecto que o diretor é mais

8 O último processo de certificação de diretores na rede estadual foi regido pelo Edital $\mathrm{n}^{\circ} 02 / \mathrm{SEE} /$ AC, de 17 de julho de 2015, para o quadriênio 2016/2020, sendo pré-requisito para inscrição: ser professores do quadro efetivo da SEE em atividade, que tenham exercido função de magistério na rede Estadual de Ensino do Acre por período de, no mínimo, 5 (cinco) anos, na condição de servidor do quadro permanente do magistério, com formação de nível superior em curso de licenciatura plena, desde que não tenham sido condenados em processo administrativo nos últimos 5 (cinco) anos, conforme o artigo $6^{\circ}$ da Lei Estadual $N^{\circ} 1.513 / 2003$. 
cobrado, segundo Souza (2010). Já 22,22\% apontaram o aspecto pedagógico e outros 22,22\% optaram pela articulação dos aspectos administrativo/político/ pedagógico e 11,11\% opinaram pelos aspectos administrativo/pedagógico. Esses dados mostram que alguns diretores se reconhecem como sujeitos políticos.

Souza (2010) não vê sentido em procurar identificar dentre as faces administrativa, política e pedagógica aquela que resume o trabalho do dirigente escolar. Para ele, todas essas faces são inatas à função. Elas devem ser trabalhadas de forma articulada com os objetivos educacionais, contudo, em algum momento, será necessário dedicar-se a uma delas em especial. No mesmo sentido, Paro (2015) afirma que é possível que as atividades-meio (administrativas) e as atividadesfim (pedagógicas) possam coexistir numa mesma atividade. $O$ autor reforça a ideia de que o importante antes de mais nada, é levar em conta os objetivos que se pretende com a educação. Então, na escola básica, esse caráter mediador da administração deve dar-se de forma a que todas as atividades-meio (direção, serviços de secretaria, assistência ao escolar e atividades complementares, quanto a própria atividade fim, representada pela relação ensino-aprendizagem que se dá predominantemente (mas não só) em sala de aula, estejam permanentemente impregnadas dos fins da educação

As atividades pedagógicas, os afazeres administrativos e as relações de trabalho são as que mais absorvem o tempo do trabalho do diretor de escola pública no Acre. Destas, a pedagógica é a mais apontada pelos dirigentes pesquisados, provavelmente por ser, reconhecidamente, o aspecto mais importante do trabalho do diretor e ser a atividade-fim da escola.

A pesquisa mostrou que as maiores cobranças e exigências quanto à atuação dos diretores recaem, principalmente, sobre a produção de resultados quantificados e de indicadores de desempenho, visando a melhorar o IDEB. Os gestores também destacam a implementação da gestão democrática, maior grau de formação e inovações pedagógicas, a necessidade de atuar como condutor das reformas escolares através da mobilização de sua equipe educativa, buscando implementar um modelo gerencial de administração baseada no funcionamento das empresas, maior rigor administrativo, mobilização dos recursos humanos e eficiência gerencial. Por fim, destacam o domínio das novas tecnologias educacionais.

As maiores cobranças, os diretores recebem na seguinte ordem: 1) da Secretaria de Estadual de Educação; 2) dos membros do Núcleo Gestor da Escolar (Coordenadores de Ensino e Coordenadores Administrativos); 3) dos Pais e Professores e 4) dos alunos. Cruz (2015) analisa essa questão da seguinte maneira: 
O diretor se vê em situações que pouco pode de fato resolver somente com sua ação, pois o cotidiano da escola é muito dinâmico, e ao trabalhar com seres humanos, há que se considerar que professores, funcionários, alunos e pais exigem do diretor respostas e ações muitas vezes diferentes, porém visando o mesmo objetivo de organizar a escola para que atinja seus objetivos (CRUZ, 2015, p.50).

Em relação aos fatores atribuídos às mudanças significativas nos indicadores e na qualidade do ensino no Estado do Acre, que vem ocorrendo nos últimos anos, os diretores apontaram os seguintes: 1) Acompanhamento, supervisão do trabalho do professor pela direção e coordenação da escola e a política de formação; 2) o modelo de gestão escolar; 3) Controle da SEE e da escola sobre o desempenho dos alunos nos exames nacionais (SAEB, prova Brasil, provinha Brasil), Plano de Carreira Profissional e condições de trabalho; 4) a Politica salarial.

Os depoimentos a seguir revelam a percepção de alguns diretores sobre a função.

\footnotetext{
"Ser diretor hoje é desafiador. Eu acho prazeroso porque gosto de desafios, porém acho que é necessário maior valorização de nossa classe. Temos apoio da SEE, porém, órgãos como Ministério Público e Conselho Tutelar cobram demais e apoiam de menos" (DIRETORA 7).

"Gosto muito do que faço. Sou realizada profissionalmente. Não vejo o trabalho como árduo, penoso, ou seja, não sou vítima da gestão. Me propus ao cargo de gestor escolar, sabedora de todos os encargos" (DIRETORA 8).

"A gestão escolar não pode ser fortalecida se a autonomia não for plena, desde o processo de lotação dos profissionais nas escolas, passando pela matrícula dos alunos e poder das decisões tomadas pelas escolas" (DIRETORA 4).
}

A função de diretor de escola pública no Acre sofreu transformações a partir da década de 1990, com as reformas educacionais e as políticas implementadas na gestão educacional, acarretando aumento nas suas atribuições. O diretor passa a administrar recursos financeiros com as escolas transformadas em unidades executoras, passa a gerenciar os conflitos, cada vez mais frequentes, entre alunos/ alunos, alunos/funcionários, em virtude do crescimento assustador da violência. Também por conta do atendimento a uma nova clientela, como é o caso dos alunos deficientes, com transtornos do desenvolvimento e altas habilidades/ superdotados, pobres, de grupos minoritários da sociedade (índios, seringueiros, ribeirinhos, etc) que, até então, encontravam-se excluídos do processo formal escolar.

As avaliações em larga escala, a criação dos indicadores de qualidade, como o IDEB, têm contribuído para essa intensificação do trabalho, pois os diretores são cobrados e responsabilizados pelos resultados da escola, inclusive prêmios de 
bonificação, como o Prêmio Anual de Valorização e Desenvolvimento da Gestão - PAVDG, são condicionados a resultados nessas avaliações e ao cumprimento de metas.

\section{FORMAÇÃO}

A formação em nível superior para ser diretor escolar na rede pública no Acre é uma exigência da Lei 1.513/03, que normatizava tal função. Todos os diretores participantes desta investigação e do quadro geral da rede pública acriana apresentam essa formação. No quadro geral dos diretores da rede acriana de ensino, num total de 252 (eleitos em 2015), 42,2\% são pedagogos e 57,8\% são formados em outras licenciaturas, confirmando o que Souza (2006, p. 210) afirma: "A Pedagogia é muito presente como principal habilitação de formação superior dos diretores".

\section{Gráfico 2 - Formação dos Diretores da Rede Estadual do Acre}

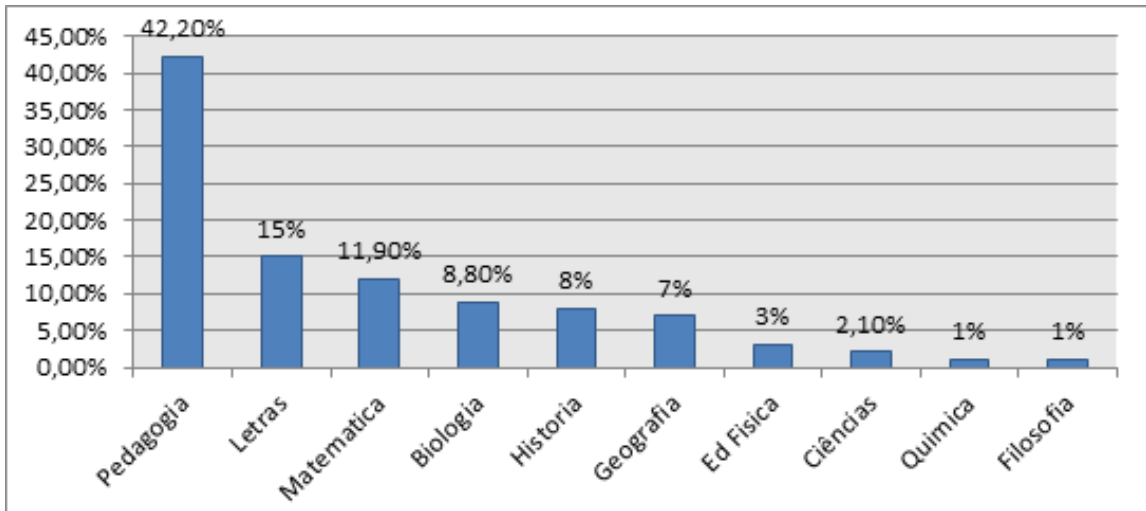

Fonte: SEE/2016 - elaborado pelos autores

Em se tratando de Pós-graduação "lato sensu", 70,8\% dos diretores de escolas públicas do Acre possuem especialização, nenhum tem mestrado e um diretor $(0,4 \%)$ tem doutorado na área de estatística. Estão assim distribuídos no que se refere à pós-graduação: 


\section{Gráfico 3 - Pós-Graduação dos Diretores da Rede Estadual}

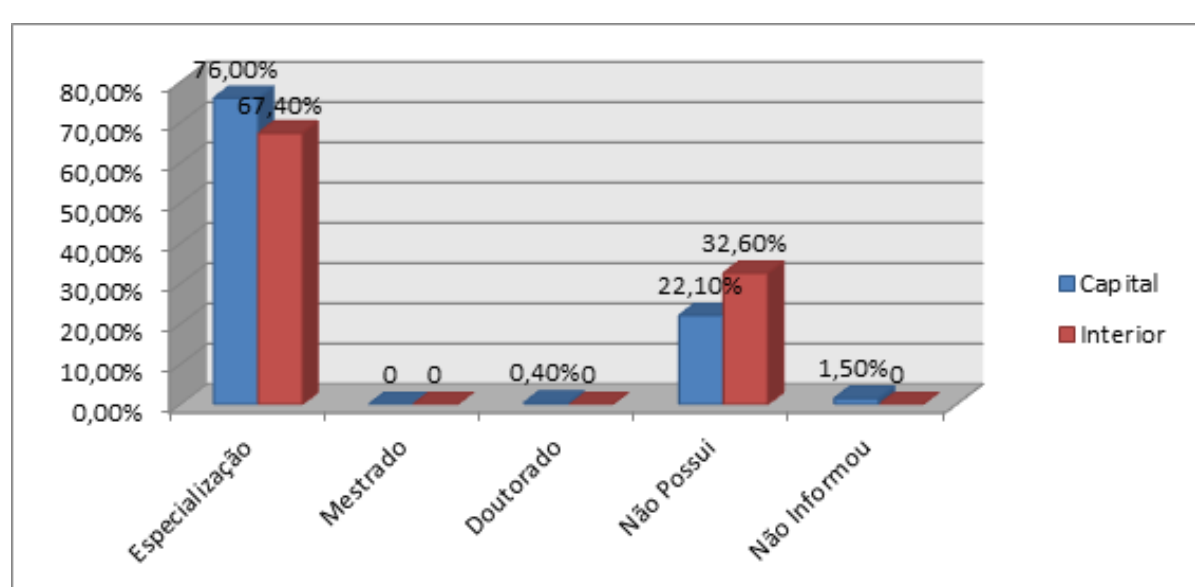

Fonte: SEE/2016 - Elaborado pelos autores

Nos dados disponibilizados pela SEE em relação à formação em pósgraduação "lato sensu", o curso predominante é na área específica de gestão escolar, considerando todas as suas variações, como pedagogia gestora, planejamento e gestão escolar, administração escolar, planejamento e gestão escolar na educação básica, gestão administrativa e gestão escolar, nos quais 72 diretores realizaram estudos, o equivalente a $28,6 \%$.

Sobre a formação específica para o diretor escolar, Paro (2003) assevera que a exigência dessa formação supõe que ela vai fornecer os conhecimentos necessários para dirigir bem a escola. O problema, segundo o autor, refere-se ao currículo das formações, principalmente no curso de pedagogia com habilitação em administração escolar, em que, quase sempre, é inadequado para dar conta da realidade da escola e sua gestão. Para ele, não há razão para privilegiar conteúdos da chamada "gerência científica" empresarial, como costuma ocorrer na formação do diretor escolar. É necessária uma formação do dirigente, como um educador, "que tenha familiaridade com os fins sociais da educação e as formas de alcançálos" (PARO, 2003, p. 86).

Os estudos de Souza (2006) revelam que a formação específica não influencia muito a prática do diretor escolar, o autor aponta que pesquisas têm constatado que não há diferença nos resultados dos trabalhos desenvolvidos por diretores com formação específica e de diretores com outra formação docente.

Noutra direção, Alonso (1976) diz que o diretor escolar necessita de uma formação complexa e especializada para dar conta de compreender os objetivos da educação com uma formação social e política para interpretar adequadamente a realidade. Compartilha-se, aqui, dessa ideia, em virtude do papel fundamental do 
diretor na contribuição da melhoria da qualidade da educação, liderando a equipe escolar na condução do Projeto Pedagógico da Escola, entre outras ações.

Souza (2006; 2010a e 2010b) diz que a formação inicial não parece ser o aspecto diferenciador de boas práticas na direção do trabalho escolar. O que poderia ter impacto seria a formação continuada, cujos conteúdos precisariam ter relação direta com a essência da função a ser desempenhada, ou seja, se o desejo é ter um diretor com natureza político-pedagógica, os conteúdos dessa formação, obrigatoriamente, deveriam focar nesse aspecto. Nesse caso, "Uma formação com enfoque gerencial e administrativo são (sic) secundadas por uma formação focada em questões relacionadas à política educacional, aos princípios do direito, à educação e à educação democrática" (SOUZA, 2010, p.176). Na questão que trata de participação em curso de formação continuada depois de eleitos, 55,5\% dos diretores disseram que participaram, enquanto 44,5\% não participaram. Esses cursos enfatizam, principalmente, aspectos administrativos (33,33\%) administrativos/político/pedagógicos (22,22\%); pedagógico (11,11\%) e administrativo/pedagógico (11,11\%).

O próprio curso de certificação oferecido na primeira etapa do processo misto (certificação/eleição) é revelador de uma formação aligeirada, oferecida pelo órgão central da educação acriana, que privilegia os aspectos administrativos do trabalho do diretor em detrimento de aspectos políticos e pedagógicos. A última formação foi oferecida por meio do Instituto Estadual de Educação Profissional Dom Moacyr, na modalidade de educação a distância, em 8(oito) módulos de aprendizagem ${ }^{9}$, por meio da internet, com duração de oitenta horas.

\section{REMUNERAÇÃO}

As escolas acrianas da rede estadual são classificadas anualmente de acordo com o número de alunos do CENSO/MEC do ano anterior (Art. 49 da Lei $1.513 / 03$ ) e o vencimento dos dirigentes regulamentado pela Lei Complementar $n^{\circ} 67 / 99$ que trata sobre cargos, carreira e remuneração dos profissionais do quadro da SEE, de acordo com essa tipificação estabelecida na Lei. As unidades escolares são classificadas em quatro tipos: a) Escola Tipo A (até 100 alunos); Escola Tipo B (101 a 900 alunos); Tipo C (901 a 2000 alunos) e Tipo D (acima de 2001 alunos). Para cada tipo de escola é definido um vencimento para seu dirigente, de acordo, também, com sua formação.

\footnotetext{
9 Os módulos abordam as seguintes temáticas: I - Fundamentos e Princípios da Educação e da Gestão Escolar; II - Planejamento e Organização do Trabalho Escolar; III - Monitoramento de Processos e Avaliação Institucional; IV - Gestão de Resultados Educacionais; V - Gestão Democrática e Participativa; VI Gestão de Pessoas; VII - Gestão Pedagógica e VIII - Gestão Administrativa.
}

826 - RBPAE - v. 33, n. 3, p. 811 - 833, set./dez. 2017 
O último reajuste da tabela salarial dos diretores escolares se deu por meio da Lei Complementar no 228/11, que vigorou até 2016, o que gerou muitas reclamações por parte dos diretores, afinal, foram cinco anos sem alteração dos vencimentos.

Tabela 2 - Tipificação das Escolas/Vencimento do Diretor

\begin{tabular}{|c|c|c|c|}
\hline CLASSIFICAÇÃO & NUMERO DE ALUNOS & DIRETOR P1(N. Médio) & $\begin{array}{c}\text { DIRETOR P-2 } \\
\text { Superior) }\end{array}$ \\
\hline TIPO A & Até 100 alunos & - & - \\
\hline TIPO B & De 101 a 900 alunos & $2.300,00$ & $5.200,00$ \\
\hline TIPO C & De 901 a 2000 alunos & $2.500,00$ & $5.700,00$ \\
\hline TIPO D & Acima de 2001 alunos & $2.700,00$ & $6.200,00$ \\
\hline
\end{tabular}

Fonte: Lei Complementar no .228 de 19 de julho de 2011 - elaborada pelos autores

Essa remuneração é considerada pelos diretores pesquisados como insatisfatória, apesar da maioria $(55,55 \%)$ dizer que é possível viver com dignidade na função. Percebe-se, aqui, uma incoerência nas respostas, pois, como é possível uma remuneração ser insatisfatória e possibilitar viver com dignidade? Considerase baixa a remuneração desses diretores, pois como diz CRUZ (2015, p.46), “a figura do diretor escolar e sua atuação vem ganhando destaque nos últimos anos como elemento de contribuição para a qualidade da educação" e que "o diretor como responsável pela gestão da escola, é o principal sujeito para a implementação das políticas que ali chegam" (CRUZ, 2015, p. 47). Era de se esperar que esse profissional do magistério, de elevada relevância no processo educativo, tivesse uma boa remuneração, como também os professores.

Compreende-se a questão salarial, a boa formação e boas condições de trabalho como fundamentais para a valorização dos profissionais. Para Paro (2000), o salário baixo é uma das causas mais importantes da baixa formação do professor, levando à queda da qualidade da força de trabalho e contribuindo para a evasão de pessoas qualificadas. Convém assinalar que uma das diretoras que participou da pesquisa não concorreu ao pleito de 2015 por essa razão, alegando que a remuneração do diretor no Acre é baixa.

Outro fator importante para análise da remuneração de um profissional é a sua jornada de trabalho. Embora obrigados a trabalhar oito horas/dia, cumprindo uma escala semanal que possibilite sua presença em todos os turnos de funcionamento da escola (como é o caso de duas escolas pesquisadas), cinco diretores $(55,55 \%)$ disseram que trabalham 10 horas/dia, um $(11,11 \%)$ trabalha 
16 horas/dia, um (11,11\%) trabalha 12 horas/dias e dois $(22,22 \%)$ trabalham 8 horas/dia, evidenciando, assim, uma sobrecarga de trabalho junto a maioria dos participantes da pesquisa.

No caso do Acre, considerando um professor com 20 anos de serviço (caso dos diretores participantes da investigação) com um contrato, cujo salário é de R\$ 3.217,52 (cf. tabela salarial vigente) e um diretor de uma escola tipo B (a maioria das escolas pesquisadas), com salário de $\mathrm{R} \$ 5.200,00$ (cf. tabela 11), a diferença salarial entre eles é de um pouco mais de $60 \%$. Nas situações onde o diretor possui dois contratos, essa diferença aumenta para cerca de $80 \%$.

\section{CONSIDERAÇÕES FINAIS}

Durante todo este texto, procurou-se colocar em relevo questões associadas ao redirecionamento dado ao Estado brasileiro por meio da Nova Administração Pública, principalmente a partir da década de 1990, e as fortes repercussões desta no sistema educacional e na forma como as escolas vêm sendo administradas. O objetivo foi dar ênfase às pesquisas que são reveladoras de especificidades presentes no modo de governança das escolas no Estado do Acre. Nesse movimento, é imperioso reconhecer que, com os governos de cunho mais popular que ocuparam o poder no Acre desde 1999, o setor educacional registrou avanços, como: maiores recursos e investimentos direcionados para a educação; foram implementadas políticas de formação inicial e continuada; planos de cargos e salários, com pisos entre os melhores do Brasil; escolas com padrão arquitetônico, que supera o padrão de muitas escolas particulares, foram e estão sendo construídas; melhoria nos índices educacionais; implementação de políticas inclusivas, etc.

Contudo, esses governos não foram capazes de romper com a lógica gerencial que informa as políticas educacionais nos últimos anos e, por conta disso, foram perdendo de vista outras racionalidades, outras concepções, outras práticas pedagógicas que poderiam muito bem presidir todo esse percurso, numa linha mais democrática e menos gerencial. Concorda-se com Oliveira (215), quando afirma que não se podem perder de vista as contradições estabelecidas no interior do próprio Estado capitalista, que pode, em determinados momentos, dar ganho de cau $\urcorner$ sa aos trabalhadores, mas não romperá com a lógica que o fundamenta, lógica essa excludente, que nunca será capaz de incluir as demandas de toda a sociedade.

Tratando mais especificamente dos casos investigados nesta pesquisa, que envolveu a função, a formação e a remuneração dos diretores no Estado do Acre, mostrou-se que a organização da função não atende aos anseios dos diretores 
da rede pública estadual. A formação inicial é considerada boa. Já a formação continuada é considerada pouca e insuficiente. No tocante à remuneração, aspecto fundamental na valorização do profissional, assim como os diretores, considerase, aqui, insatisfatória, baixa e injusta, diante das atribuições e reponsabilidades de um diretor escolar, a remuneração adequada torna-se um desafio para a educação no Estado do Acre. Com uma tabela de vencimentos congelada há mais de quatro anos, com pequena diferença em relação ao salário do professor, o diretor de escola no Acre amarga dissabores e insatisfações em relação à sua remuneração, o que os deixa desmotivados, situação apontada por diretores que participaram desta pesquisa.

Em Julho de 2016, O Governo do Acre aprovou a Lei 3.141/16, que "dispõe sobre a gestão democrática das unidades escolares da rede pública estadual de educação básica do Acre”. A partir de então, novas perspectivas em relação à função, à formação e à remuneração do diretor de escola pública no Acre se vislumbram, o que permite afirmar que este assunto não se esgota. Novas pesquisas são necessárias para revelarem a dinâmica da gestão escolar nas escolas acrianas, o que, por hora, não pode ser respondido nos limites deste artigo.

\section{REFERÊNCIAS}

ACRE. Constituição do Estado do Acre - 1989. Assembleia Legislativa do Estado do Acre. Rio Branco. Disponível em: <http://www.aleac.ac.gov.br $>$. Acesso em 01/07/2015.

Lei $\mathrm{n}^{\circ} 1.513$ de 11 de novembro de 2003. Dispõe sobre a gestão democrática do sistema de ensino público do Estado do Acre e dá outras providências. Disponível em: www.al.ac.gov.br. Acesso em: 10/09/2015.

Lei $\mathrm{n}^{\mathbf{0}}$ 1.201/96. Institucionaliza a gestão democrática do sistema de ensino público do Estado do Acre e dá outras providências. Disponível em: www. al.ac.gov.br. Acesso em: 10/09/2015.

Lei $\mathrm{n}^{\mathrm{o}} \mathbf{1 . 5 1 3}$ de 11 de novembro de 2003. Dispõe sobre a gestão democrática do sistema de ensino público do Estado do Acre e dá outras providências. Disponível em: www.al.ac.gov.br. Acesso em: 10/09/2015.

Instrução Normativa $\mathbf{n}^{\circ}$ 004/2004. Estabelece diretrizes administrativaspedagógicas no âmbito das escolas da rede estadual de ensino. Disponível em: www. see.ac.gov.br. Acesso em: 12/09/2015. 
Lei Complementar $\mathbf{n}^{\mathbf{0}}$ 14/1987 que dispõe sobre a criação do Plano de Cargos, Salários, Benefícios e Vantagens do Magistério Acreano e dá outras providências. Disponível em: www.al.ac.gov.br. Acesso em: 11/09/2015.

Lei Complementar $n^{\circ} 67$ de 29 de Junho de 1999. Dispõe sobre o Plano de Cargos, Carreira e Remuneração dos profissionais do Ensino Público Estadual e dá outras providências. Disponível em: www.al.ac.gov.br. Acesso em: $11 / 09 / 2015$.

Lei $\mathrm{n}^{\circ} 228$ de 19 de Julho de 2011. "Concede reajuste salarial aos servidores ativos, inativos e pensionistas da Secretaria de Estado de Educação e Esportes - SEE.”. Disponível em: www.al.ac.gov.br. Acesso em 2/12/2015.

Lei Complementar n 3.141 de 22 de Julho de 2016. "Dispõe sobre a gestão democrática das unidades escolares da rede pública estadual de educação básica do Acre”. Disponível em www.al.ac.gov.br. Acesso em 10/08/2017.

Decreto $n^{\circ}$ 3.191, de 19 de Agosto de 2014. Regulamenta o Prêmio Anual de Valorização e Desenvolvimento Profissional (VDP) dos servidores da Secretaria de Estado de Educação e Esporte de que trata o artigo 23-D da lei Complementar Estadual no 67 de 29 de Junho de 1999, acrescido pela Lei Complementar $\mathrm{n}^{\circ}$ 285, de 11 de Abril de 2014. Diário Oficial do Estado do Acre. Rio Branco-AC, 20 de agosto de 2015. Disponível em: www.diario.ac.gov.br. Acesso em 5/02/2016.

Decreto no. 5.592, de 16 de Agosto de 2010. Regulamenta o Prêmio Anual de Valorização e Desenvolvimento Profissional - PAVDP, de que trata o art. 23-A, da Lei Complementar no 67, de 29 de junho de 1999. Disponível em: www.diário.ac.gov.br. Acesso em 5/02/2016.

Acre em números 2013. 9. ed. Disponível em: www.ac.gov.br/wps/wcm/ connect/e0c7fd0042426ebe9196b371c3911451/Acre2bNúmeros\%2B2013. Acesso em: 30/11/2017.

ALONSO, M. O papel do diretor na administração escolar. São Paulo, DIFEL, EDUC, 1976.

BARROSO. J. O estado, a educação e a regulação das políticas públicas. Educação e Sociedade. Campinas, vol. 26, nº 92, p. 725-751, Especial - Out. 2005. 
BASSI, M.E.; DEBOVI, A.; SANDRINI, N.M.S. Carreira e remuneração do magistério público da educação básica no sistema de ensino estadual de Santa Catarina. Educação em Foco. Ano 15. N.19 junho, 2012. P. 57-80.

BALL, S. J. Cidadania Global, Consumo e Política Educacional. In: SILVA, L. H. da (Org). A Escola Cidadã no contexto da globalização. Petrópolis: Vozes, 1998. p. 121-137.

BRASIL. Constituição Federal de 1988. República Federativa do Brasil: Senado Federal, Centro Gráfico, 1988.

Lei n. 11.738, de 16 de julho de 2008. Regulamenta a alínea "e" do inciso II do caput do art. 60 do Ato das Disposições Constitucionais Transitórias, para instituir o piso salarial profissional nacional para os profissionais do magistério público da educação básica, Disponível em: http://www.presidência.gov.br/ legislação/. Acesso em 20/11/2016.

Lei $\mathbf{n}^{\circ}$ 9.394/96. Estabelece Diretrizes e Bases da Educação Nacional. Disponível em: portal.mec.gov.br/arquivos/pdf/ldb.pdf. Acesso em:10/09/2016.

Lei $\mathrm{n}^{\circ} \mathbf{8 . 1 1 2}$ de 11 de Dezembro de 1990. Dispõe sobre o regime jurídico do servidores públicos civis da união, autarquias e das fundações públicas federais. Disponível em: www.planalto.gov. br/ccivil. Acesso em: 20/09/2016.

CASTRO, A. M. D. A. Accoutability e Empoderamento: estratégias gerenciais na escola. Disponível em www.anpae.org.br/congressos_antigos/simposio2007/12. pdf. Acesso em: 01/08/2017.

CRUZ, J. L. de O. O Provimento do Diretor nas Escolas Públicas Brasileiras e suas Implicações na Gestão Escolar. 2015, 125 f. Dissertação de Mestrado. Programa de Pós-Graduação em Educação da Universidade Federal do Paraná.

DAMASCENO, E. A. O Trabalho Docente no Movimento de Reformas Educacionais no estado do Acre. 2010. Tese (Doutorado em Educação). Universidade Federal de Minas Gerais, Belo Horizonte.

FREITAS. L. C. Políticas de Responsabilização: entre a falta de evidência e a ética. Cadernos de Pesquisa. V. 43, n 148, p. 348-365, jan./abr. de 2013. 
Instituto Brasileiro de Geografia e Estatística. Senso Demográfico 2010. Rio de Janeiro, IBGE, 2010.

LIBÂNEO, J. C. Organização e gestão da escola: teoria e prática. Goiânia: Editora Alternativa, 2001.

LIMA, I. G. e GANDIN, L.A. Entendendo o estado gerencial e sua relação com a educação: algumas ferramentas de análise. Práxis Educativa, Ponta Grossa, v. 7, n.1, p.69-84, jan/jun.2012

MELO, L. F. Reformas educacionais e gestão democrática no Estado do Acre: repercussões no trabalho do núcleo gestor da escola. 2010. 357 f. Tese (Doutorado em Educação) - Universidade Federal de Minas Gerais, Belo Horizonte-MG.

OLIVEIRA, D. A. A reestruturação do trabalho docente: precarização e flexibilização. Educ. Soc., Campinas, vol. 25, n. 89, p. 1127-1144, Set./Dez. 2004 1127. Disponível em http://www.cedes.unicamp.br

D.A. Regulação das políticas educacionais na América Latina e suas consequências para os trabalhadores docentes. Educação e Sociedade, Campinas, vol. 26, n.92, p.753-775, Especial - out, 2005.

D.A. Os trabalhadores da educação e a construção política da profissão docente no Brasil. Educar em Revista. Curitiba, Brasil, n. especial 1, p.17-35, 2010. Editora UFPR>

D. A. Nova Gestão Pública e Governos Democrático-Populares: contradições entre a busca da eficiência e a ampliação do direito à educação. Educ. Soc., Campinas, v. 36, nº. 132, p. 625-646, jul.-set., 2015

PARO. V. H. Gestão Democrática da escola pública. 3.ed. São Pulo: Ática, 2000 .

V. H. Eleições de Diretores: A Escola pública experimenta a democracia. 2. Ed. São Paulo: Xamã, 2003.

V. H. Diretor escolar: educador ou gerente? São Paulo: Cortes, 2015. 
SHIROMA, E.O. Implicações da política de profissionalização sobre a gestão e o trabalho docente. Revista Trabalho \& Educação, v. 13, n 02. Ago/ dez, 2004.

SOUZA, A.R. Perfil da gestão Escolar no Brasil. 2006. 285 f. Tese de Doutorado (Educação: História, Política, Sociedade). PUC-São Paulo.

A.R e GOUVEIA. A.B. Diretores de escolas públicas: aspectos do trabalho docente. Educar em revista. Curitiba. Brasil. n. especial 1. P. 173-190, 2010a. Editora UFPR.

A.R. Diretor escolar. In: OLIVEIRA, D.A. DUARTE, A.M.C. VIERIA, L.M.F. Dicionário: trabalho, profissão e condição docente. Belo Horizonte: UFMG/Faculdade de Educação, 2010b. CDROM.

LÚCIA DE FÁTIMA MELO é Graduada em Pedagogia pela Universidade Federal do Acre (1992); Especialista em Currículo e Avaliação Educacional pela Universidade Federal do Acre (1996); Mestra em Educação pela Universidade Federal do Rio de Janeiro (2002). Doutora em Educação no Programa em educação, conhecimento e inclusão social da UFMG na linha de pesquisa: Políticas Públicas Educacionais: concepção, implementação e avaliação (2010). Professora adjunta da Universidade Federal do Acre, lotada no Centro de Educação, Letras e Artes, onde atua na Graduação nas seguintes áreas: Organização da Educação Básica e Legislação do Ensino; Gestão Escolar e Organização Curricular e Gestão da Escola e na Pós Graduação "Stricto Sensu", Mestrado em Educação, onde ministra a disciplina Estado, Políticas Públicas e Educação e orienta estudos com foco nas políticas educacionais e na gestão escolar. Vice Líder do Grupo de Estudos e Pesquisas em Política Educacional, Gestão Escolar, Trabalho e Formação Docente - GEPPEAC, com pesquisas nas linhas: políticas educacionais e gestão escolar. E-mail: lucia.educa@bol.com.br

MÁRIO ROBERTO MACHADO TORRES é Graduado em Pedagogia pela Universidade Federal do Acre (1999). Especialista em Gestão Escolar (2001) e Mestre em Educação pela Universidade Federal do Acre (2016). Professor na Secretaria Estadual de Educação e especialista em Educação na Secretaria Municipal de Educação de Bujari/AC. Tem experiência na área de Educação, com ênfase em Administração de Sistemas Educacionais, Direção de Unidades Escolares, Docência na Educação Básica e no Ensino Superior e na Formação de Professores. E-mail: mariobujari@hotmail.com 